\title{
A CONCISE PICTURE OF HERNIA
}

\author{
ATHIRA ROY, KRISHNA RAVI*, REEJA T REJI
}

Department of Pharmacy Practice, J. K. K. Nattraja College of Pharmacy, Namakkal, Tamil Nadu, India. Email: drkrishnaravi.7kr@gmail.com

Received: 18 September 2021, Revised and Accepted: 10 November 2021

ABSTRACT

A hernia is a disease wherein organs or tissues, like the bowel, bulge through the abdominal wall. The etiological, as well as precipitating factors for hernia include abdominal pressure, pre-existing weakness of abdominal muscles, gender, obesity, age, diet, lack of regular exercise, and smoking. Swelling, stiffness, and discomfort seem to be the most prevalent hernia symptoms, particularly while straining, moving, or bending down. Open and laparoscopic techniques are mainly used for hernia repair, both use mesh to counterbalance the abdominal wall flaws and provide a tension-free restoration.

Keywords: Hernia, Abdomen, Weakness, Pain.

(c) 2021 The Authors. Published by Innovare Academic Sciences Pvt Ltd. This is an open access article under the CC BY license (http://creativecommons.org/ licenses/by/4.0/) DOI: http://dx.doi.org/10.22159/ajpcr.2021v14i12.43177. Journal homepage: https://innovareacademics.in/journals/index.php/ajpcr

\section{INTRODUCTION}

A hernia is a condition in which tissues or organs such as the bowel, protrude through the abdominal wall [1,2]. A hernia is often associated with abdominal issues which are usually easy to diagnose by simply feeling for a protrusion and looking for it [3]. The most common types of hernias are inguinal hernia (inner groin), umbilical hernia (belly button), femoral hernia (outer groin), incisional hernia (groin), hiatal hernia (upper stomach), and epigastric hernia (epigastric region). According to the National center for Health Statistics 2015 report abdominal hernias is a common problem in the general population with an occurrence rate of $1.7 \%$ across all ages, and it increased by $4 \%$ for those over 45 [4]. Inguinal hernias account for approximately $75 \%$ of all hernias, with an incidence rate of $27 \%$ in men and $<3 \%$ in women [5-7]. The most common symptoms are swelling, heavy sensation, and discomfort, particularly while straining, moving/ bending down and it mainly occurs in the abdomen, groin regions, navel area, and upper thigh [8]. Etiological, as well as precipitating factors for hernia, includes abdominal pressure, pre-existing weakness of abdominal muscles, gender, obesity, age, diet, lack of regular exercise, smoking, and comorbidities such as chronic obstructive pulmonary disease (COPD), congenital abnormalities, previous abdominal surgery/trauma, hernia history in the family, and grand multi Para [9-11]. The diagnosis of hernia includes a detailed physical examination, abdominal ultrasound, computed tomography (CT) scan or magnetic resonance imaging (MRI), and using dynamic sonography [12]. The treatment goal is to improve the standard of living and to prevent a recurrence, adverse events such as incarceration while keeping the rate of surgical complications low [13-15]. Each year, more than 20 million hernias are projected to be operated on around the world [8]. Today, both open and laparoscopic hernia repair techniques are used, and both use a prosthetic mesh to fill the flaws in the abdominal wall and achieve a tension-free restoration [16]. Postoperative complications include wound infection, chronic pain, groin edema, urinary retention, bladder injury, and anesthetic complications such as post-spinal headache. Late complication includes recurrence, neuropraxia, hydrocele, and even death $[17,18]$.

\section{DATA SOURCE AND SEARCH STRATERGY}

The databases such as PUBMED, SCOPUS, ELSEVIER, and EMBASE were searched using the applicable Medical Subject Headings (MeSH) and subheadings. This was incorporated into the keyword searches.
Search terms included abdominal pressure, weakness, pain, risk factors, complication, hernia repair, and hernia medication. A total of 112 articles were obtained from the databases. From 112 articles 91 articles met the criteria and were assessed and the others were excluded from the study. After that, the review was prepared from the contents extracted from those articles.

\section{INCIDENCE OF HERNIA}

As per the report of The National Institute of Health the surgical description of hernias and treatment dates back to ancient Egypt. Although there was written proof of patients suffering from inguinal hernia as early as 1500 B.C., the hernia was likely a surgical disease long before that. Due to a lack of data from poor nations, the frequency and prevalence of certain diseases is unknown. Hernias are thought to be distributed similarly by gender and anatomical location in developed countries. In adults, the majority of hernias occur in the groin. Indirect inguinal hernias are the most prevalent hernias in both men and women, according to the Asia Pacific Hernia Society (Aphernia) 2020 figures; there is a right-sided predominance. Inguinal hernia accounts for about $75 \%$ of all hernias. Incisional and epigastric hernia describes for about $10 \%$ of all hernias. $5-7 \%$ umbilical, femoral hernias account for only $3 \%$ of all hernias and its incidence is 4 times higher in females than males [9]. Abdominal wall hernias affect between $10 \%$ and $30 \%$ of children; the majority of these hernias resolve spontaneously by the age of 1 year [4].

\section{AGE AND SEX}

Indirect hernias usually emerge within the $1^{\text {st }}$ year of life; however, they may not appear until the middle or later years. Because the musculature of the abdominal wall relaxes and the fascia thins in older people, direct hernias develop more in older people. It rarely occurs in young adults [19]. Umbilical hernias are most common in infants, and they normally grow to their full size within the $1^{\text {st }}$ month. The majority of these hernias resolve spontaneously by the $1^{\text {st }}$ year of life, with just a $2-10 \%$ occurrence in children older than 1 year [20]. Males account for approximately $90 \%$ of all inguinal hernias. Femoral hernias (rare) are more common in women because of the variances in the pelvic anatomy between men and women. Obturator hernias have a 6:1 female-to-male ratio. This is linked to a gender-specific greater canal diameter; elderly people are much more likely to develop this hernia. 


\section{TYPES OF HERNIA}

The abdominal wall is made up of layers rather than a single muscle sheet. When the abdominal muscle weakens, a portion of the intestine bulges through and appears as a lump under the skin. Figure 1 represent different types of hernia based on their location. Inguinal hernias are the most prevalent type of hernia and it occurs in the groin $[21,22]$.

\section{Inguinal hernia}

It is the most common form of hernia. Most commonly occurs in the groin, attributing about more than nine out of ten hernias. The inguinal ring of muscle in the groin is pushed against by a loop of the intestine, which eventually splits the muscle fibers apart. Inguinal hernias affect more men than women and are particularly common in middle age and old age [23]. It can account for about $75 \%$ of all hernias; two-third of these hernias is indirect and onethird direct [24].

It is an indirect inguinal hernia that travels through the inguinal canal from the abdomen to the scrotum [25].

The direct inguinal hernia arises where the abdominal wall is thinner on the interior of the indirect hernia. It will only rarely descend to the scrotum. Inguinal hernias can occur at any stage of life but it happen more often in babies who born early (Indirect Inguinal hernia). They are more common on the right side [26,27].

\section{Femoral hernia}

A femoral hernia occurs in the femoral canal [28]. Femoral hernias are less frequent than inguinal hernias [29]. This hernia generates a protrusion on the inside side of the thigh, below the inguinal canal. Intestines force through the weak muscle ring at the femoral canal until they protrude. Due to differences in pelvic anatomy, femoral hernias are more common in women.

\section{Umbilical hernia}

A part of the gut propels through a muscular weakness near the navel, or belly button. Newborns are the most common victims of this type of hernia. Although umbilical hernia repair is often considered a simple operation, recurrence rate is considered to be higher than the others. Mayo clinic report suggest that recurrence rate of umbilical is up to $50 \%[30,31]$.

\section{Hiatal (hiatus) hernia}

Through an incision in the diaphragm, a piece of the stomach climbs up into the chest cavity [32].

Hernias can also be divided into the following categories:

\section{Incisional hernia}

Tissue pushes its way through the scar from an abdominal or pelvic procedure. Incisional hernias are a common complication of laparotomy incisions [33].

\section{Epigastric hernia}

Between the navel and the lower section of the sternum, fatty tissue pushes through the abdominal area. Epigastric hernia is a hernia in the midline of the anterior abdominal wall between the umbilicus and the xiphisternum and through a defect in the linea alba [34].

\section{Spigelian hernia}

The intestine protrudes below the navel on the side of the abdominal muscle. A Spigelian hernia is a rare hernia through the Spigelian fascia between the rectus muscle and the semilunar line [35]. Symptoms vary from insidious to localized pain, an intermittent mass, and/or a bowel obstruction [36].

\section{Diaphragmatic hernia}

Birth defect in which there will a hole in the abdomen. Through the opening in the belly, organs in the abdomen can travel upward into the chest [37].

\section{CAUSES OF HERNIA}

A combination of muscular weakness and strain causes hernias [38]. Some common causes are:

- Congenital

- Aging

- Damage from an injury or surgery

- COPD

- Arduous exercise or lifting heavyweights

- Pregnancy, mainly possess multiple pregnancies

- Constipation

- Being overweight or obese

- Fluid in the abdomen, or ascites [39].

\section{RISK FACTORS $[40,41]$}

Figure 2 diagrammatically represent risk factors for hernia.

\section{Symptoms of hernia}

The prevalent symptom is a visible bump or protrusion [42]

Other common symptoms of hernias include:

- A dragging sensation or heaviness

- Pain - intermittent or continuous

- Occasional digestive upsets

- Hernia can be called reducible if the lump pushes back into the abdomen. If the lump persists, it is an irreducible hernia [43].

The signs and symptoms of a reducible hernia may include:

- A perceivable lump or an enlarged area

- A massive unbearable perception in the gut

- Pain or ache while lifting or carrying heavy objects [44]

- Digestive upsets, such as constipation

- The mass dissipates when the person is lying down [44].

Symptoms of irreducible hernia may include:

- Painful growth

- The growth that cannot be replaced [45]

- The pain could be more serious if the blood supply is break off

- Nausea and vomiting could be presenting symptoms if the bowel is obstructed or blocked [46].

\section{HERNIA DIAGNOSIS}

The primary diagnosis includes a detailed physical examination. During this examination, the physician may look for a swell in the abdominal or groin area $[47,48]$. Doctors will take a medical history. There will be a variety of questions, including things like:

- When did you first notice the bulge?

- Have you experienced any other symptoms?

- According to you what could be the cause for this?

- Describe lifestyle. Does your occupation involve heavy lifting? Do you exercise vigorously? Do you have a history of smoking?

- Does any among your family members diagnosed with hernias?

- Do you ever have surgeries done in the area of your abdomen or groin?

Imaging tests used for diagnosis include:

- Abdominal ultrasound. The clinical application of ultrasound had shown great promise. Ultrasound has a sensitivity of better than $90 \%$ for detecting groin hernias and the specificity of $82-86 \%$ [49-52].

- CT scan and MRI scan, physician consider MRI and CT scan in the workup of patients with activity-related groin pain [53,54].

- Barium X-ray, a sequence of X-ray images of the digestive tract using barium. After finishing a liquid containing liquid barium solution, the photographs are taken. Both are visible on X-ray scans [55].

- Endoscopy is a procedure in which a small camera linked to a tube is threaded down your throat, up to your esophagus, and into your stomach [46]. 


\section{PATHOPHYSIOLOGY}

\section{Common}

A weakening or deficiency in the abdominal wall can be congenital, acquired, or caused by trauma

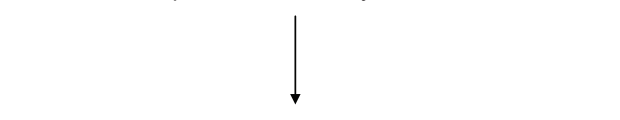

Intra-abdominal pressure rises as a result of risk factors

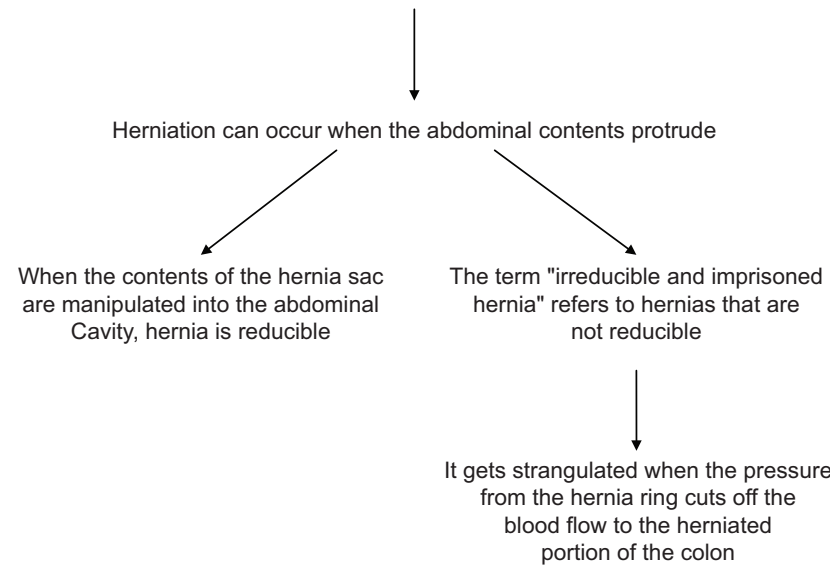

\section{Inguinal hernia}

The internal ring musculature's primary function is to keep the intestine from protruding during abdominal muscular straining. This process might be hampered by muscle paralysis or injury [56]. Repetitive stress is also a factor in hernia development. Increased intra-abdominal pressure is linked to the development of hernias in a range of diseases. Increased intra-abdominal pressures are related to the chronic cough, ascites, and increased peritoneal fluid from biliary atresia, peritoneal dialysis, or ventriculoperitoneal shunts, and intraperitoneal masses [16]. In 1981, Cannon and Read found that the increased serum elastase and decreased alpha ${ }_{1}$-antitrypsin levels associated with smoking contribute to an increased rate of hernia in heavy smokers. The role of biochemical or metabolic variables in the development of inguinal hernias is still a subject of debate [57].

\section{Femoral hernia}

A femoral hernia occurs in the femoral canal. The canal lies medial to the femoral vein and ligament. Femoral hernias usually become imprisoned because they extend through a specified area [58]. Malformed perihernial fasciae or muscles are possible [59].

\section{Umbilical hernia}

An umbilical hernia is caused by a congenital defect in the umbilical fibromuscular ring. If they last in children aged 2-4 years, they are restored $[60,61]$. Although the failure of the umbilical ring to close causes umbilical hernias in children, only one in ten adults with umbilical hernias had this problem as a child. Multiparty and increased abdominal pressure is also associated with umbilical hernias. Congenital hypothyroidism, fetal hydantoin syndrome, and disorders of collagen are the other factors.

\section{Richter hernia}

A Richter hernia occurs when the anti-mesenteric border of the bowel herniates. This hernia mainly occurs in the bowel. Richter hernias are more deadly than ordinary abdominal hernias because a piece of the bowel is strangulated, resulting in perforation and peritonitis [62].

\section{Incisional hernia}

An incisional hernia is a type of hernia that occurs when a hole is made in the skin. It is a secondary condition that occurs in $2-10 \%$ of all abdominal operations. Even after repair, the chance of recurrence is higher [8].

\section{Obturator hernia}

It is more prevalent in the elderly and in the female gender (because of a larger canal diameter). It occurs in the obturator canal. A bowel blockage rather than a protrusion of bowel contents is the most prevalent symptom of an obturator hernia $[63,64]$.

\section{Other hernias}

Other main causes of hernias include multiparity and age-related pelvic floor laxity [65]. Spigelian hernia formed due to a defect in the spigelian fascia. Obesity, increased intra-abdominal pressure, aging, and rapid weight loss are the main causes of this hernia [66]. Defective closure of the developing anterior wall at the umbilical stalk is the underlying embryogenic factor in omphalocele and gastroschisis [67].

\section{TREATMENT STRATEGY FOR HERNIA}

- Indications for surgery and urgency of treatment

- Organizing surgical care

- Techniques of hernia repair

- Local anesthesia

- Aftercare complications and outcome

- Information for patients.

\section{SURGERY FOR HERNIA}

- To avoid complications such as irreducibility and strangulation, all hernias are routinely treated surgically [68]

- Every hernia is treated differently depending on the patient's condition $[69,70]$

\section{Reducible hernias}

- To avoid the risk of strangulation in the future, all reducible hernias should be surgically corrected [71-73]

- If pre-existing medical issues make surgery risky, the doctor may elect to not treat the hernia but instead offer a temporary support belt. The patient will be monitored regularly to check whether the underlying condition subsides or not [74].

\section{Irreducible hernias}

- Because of the heightened risk of strangulation, all irreducible hernias require emergency surgery $[75,76]$

- If the bowel becomes gangrenous due to a lack of blood supply during surgery, that portion of the intestine is resected [77]

\section{Strangulated hernias}

- All strangulated hernias need emergency surgery

- A necrotic hernia or strangulation needs bowel resection.

\section{Types of surgical procedures}

- Abdominal open repair surgery: Done by creating small incisions over the herniated area [77]

- Laparoscopic surgery: is done through a keyhole puncture. It is a minimally invasive procedure. The surgery can be done in the outpatient setting, and could only take around an hour. The method of repair will depend on the individual's situation [77]

- Different techniques employed for hernia repair are:

- Herniotomy is the preferred treatment for Small Reducible Hernia. Here the contents of the hernial sac will be returned to the abdomen and close the opening. This procedure is commonly performed laparoscopically [76]

- Another surgical procedure is herniorrhaphy or hernioplasty, where weakened areas are reinforced with sutures, or a mesh wire (sheet made of synthetic material usually called Prolene mesh). This is mainly used for large irreducible hernias [76]

\section{Abdominal open repair surgery}

- This is the surgery of choice for all irreducible or strangulated hernias [78]. 


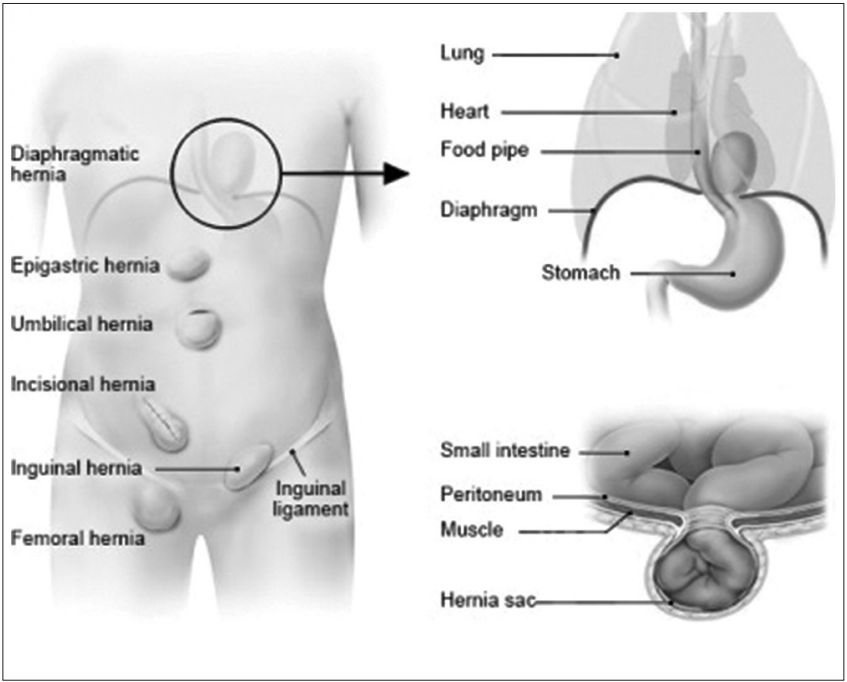

Fig. 1: Types of Hernia [22]

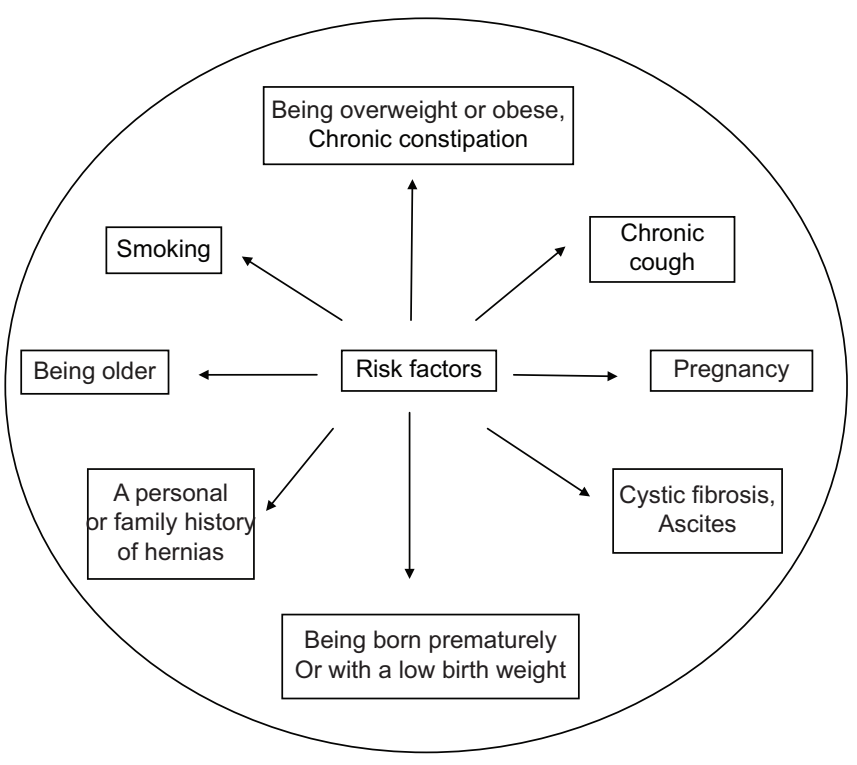

Fig. 2: Risk factors of hernia

Table 1: Do's and don'ts after hernia surgery

\begin{tabular}{ll}
\hline Do's & Don'ts \\
\hline Take mild walks & $\begin{array}{l}\text { Avoid lifting heavy weights for a } 3 \text { to } \\
4 \text { months }\end{array}$ \\
Do some stretch exercises & $\begin{array}{l}\text { Avoid smoking } \\
\text { Eat lot of fiber and }\end{array}$ \\
vegetable and drink enough & Avoid running up the stairs \\
fluids & Avoid strenuous exercises \\
\hline
\end{tabular}

\section{Laparoscopic surgery}

This procedure is performed under general anesthesia. To observe the interior structures, the abdomen is inflated with a safe gas (such as carbon dioxide). The procedure begins with several small abdominal incisions, in which the laparoscope and other surgical tools were inserted. A laparoscope is a thin, telescope-like instrument. A camera, which is attached to the laparoscope, captures, and produces continuous images. Using laparoscopic surgical equipment, the hernial sac is cut and tied. In this posture, the intestines inside the hernia sac is forced back into the muscular wall. To complete the repair the muscle wall is reinforced with stitches or synthetic mesh. Small abdominal incisions heal quickly, and the incision is barely noticeable after a few months [79].

Laparoscopic hernia surgery has the following advantages:

- Three tiny scars are made for laparoscopic repair instead of a single larger incision made for abdominal repair

- Reduced post-operative pain

- Faster return to work

- It has a shorter recovery time compared to abdominal open repair surgery and the patient can early get back into their daily activities.

\section{HERNIA MEDICATIONS}

\section{Antibiotics}

- Ampicillin $1.5 \mathrm{~g}$ is used along with gentamicin $(240 \mathrm{mg}$ diluted in $10 \mathrm{ml}$ saline) given intravenously for prophylaxis to prevent infection

- Multiple regimens of cefoxin 1-2 g can be used for bowel perforation and ischemic bowel.

\section{Local anesthetics}

- Lidocaine is used in a $0.5-1 \%$ concentration; it is combined with $0.25 \%$ bupivacaine [80].

\section{General anesthetics}

- Propofol $10 \mathrm{mg} / \mathrm{ml}$ IV produces rapid sedation, usually within $40 \mathrm{~s}[81,82]$

- Thiopental $25 \mathrm{mg}$

\section{Antianxiety agents}

- Lorazepam and midazolam can be used for patients who experience significant anxiety before surgery $[83,84]$.

\section{Non-steroidal anti-inflammatory drugs (NSAIDS)}

- Ibuprofen is the treatment of choice for patients with mild to moderate pain

- Others include diclofenac, sulindac, naproxen, meloxicam, and ketoprofen.

\section{Analgesics}

- Acetaminophen is the preferred pain reliever in patients who are hypersensitive to NSAIDs or who have an upper gastrointestinal illness

- Others include hydrocodone and tramadol

- For hiatal hernia, over-the-counter and prescription medications that reduce stomach acid can relieve discomfort and improve symptoms. These include proton pump inhibitors, $\mathrm{H}-2$ receptor blockers, and antacids.

\section{POST-SURGICAL PATIENT CARE}

The current standard of care after hernia repair is general wound care $[85,86]$. Who have had a simple hernia repair may be able to go home within a few hours or the next day. However, in more complicated circumstances, the patient may need to stay in the hospital for a few days longer. Patients usually feel good within a few days of surgery and can resume normal eating habits and activities. Exercises are advised after hernia repair as it works to strengthen muscles around the hernia and promote weight loss, helping reduce some symptoms. Heavy exercises and activities that strain the abdomen, such as weight lifting, are prohibited for 4-6 weeks after surgery because they may increase pressure in the hernia area [87]. Table 1 represent Do's and Don'ts after hernia Surgery.

\section{Home remedies}

Home remedies will not cure hernia, but some things can do to help with symptoms. Constipation, which can cause straining during bowel motions, may be relieved by increasing fiber intake. Symptoms of a hernia can be controlled with dietary changes and by avoiding large or heavy meals. Others include not lying down or bending over after a meal, maintaining healthy body weight, and quitting smoking [21]. To 
prevent acid reflux, avoid foods that could make you sick, such as spicy and tomato-based foods.

\section{WHAT ARE HERNIA COMPLICATIONS?}

Incarceration is the major complication of a hernia, where a piece of bowel or fat gets stuck in the hernial sac which cannot be reduced. Swelling and pain can occur to the point where the tissue's blood supply is cut off, and it dies. This is referred to as a strangulated hernia. It can obstruct the bowel and can cause severe pain, nausea, or constipation [88]. Others include a bulge that turns color to red or purple, fever, bleeding, infection, urinary retention, bladder injury, scrotal edema, and anesthetic complications like a post-spinal headache. In rare case, intra-abdominal tumors may herniate through weak portions of the abdominal wall [89]. Late complication includes recurrence, neuropraxia, hydrocele, and even death [90].

\section{PROGNOSIS OF HERNIA REPAIR}

The prognosis depends on the size and type of hernia as well as on the ability to reduce risk factors associated with it. Complications such as strangulation and intestinal blockage are more likely as people get older, their hernias last longer, and their irreducibility lasts longer. Abdominal hernias usually do not recur in children. They do reappear, however, in about 10 percent of adults [68]. The complications associated with inguinal hernias occur rarely in those children who were diagnosed later in childhood or whose hernias were strangulated [67].

\section{HERNIA IN BABIES}

The National Centre for Biotechnology Information 2019 Observer reports that between 10 and $30 \%$ of babies are born with an umbilical hernia. Umbilical hernias are common in babies who are born prematurely or born with low birth weight. Umbilical hernias are a type of hernia that develops near the belly button. They arise when the muscles that surround the umbilical cords hole do not shut properly. A part of the intestine may also protrude as a result of this. Umbilical hernia can be noticed more when crying or coughing [79]. Umbilical hernias in children are usually painless. However, when symptoms such as pain, vomiting or swelling at the hernia site occur, the baby should seek emergency medical attention. Umbilical hernias normally go away by the time a child is 1 or 2 years old. If it does not go away by the age of five, surgery can be done to fix it [91]. If minor hernias exist before or during pregnancy and begin to grow or cause discomfort, surgery may be recommended to treat them. The second trimester is the best time to do this [92]. Hernias can also occur following a cesarean delivery. During a cesarean delivery, an incision is made into the abdomen and uterus. An incisional hernia can sometimes occur at the location of cesarean delivery.

\section{CASE REPORTS}

A rare case of enormous growth in the right scrotum was reported in a 2-month old infant. On physical examination, the mass was found to be $10 \mathrm{~cm}$ in diameter and had episodes of vomiting with green fluid. During laparotomy investigation, an inguinal sac with intestine and appendix contents was discovered. During histopathology examination, the morphological feature shows an appearance of the mesenteric chylous cyst. An unusual case report of Type II Amyand's hernia with an enlarged mesenteric chylous cyst [93].

A 72- year-old male presented with complaints of swelling on both sides of the groin for the past 40 years. The patient had undergone bilateral inguinal hernia suture repair 50 years ago. On physical examination, the left groin had swelling of $10 \mathrm{~cm}$ in diameter, while the right groin had swelling of $3 \mathrm{~cm}$ in diameter. CT showed herniation in the left groin. The patient was diagnosed with persistent mullerian duct syndrome caused by a unique case of bilateral recurrent inguinal hernia, which was treated with transabdominal preperitoneal repair [94].

\section{CONCLUSION}

Early detection and treatment are essential to decrease the morbidity and mortality associated with hernia. This review is intended to provide an overview of hernia and its current treatment method. The present study will provide technical mastery in confirmatory to the existing guidelines, for both medical practitioners and patients dealing with this disease. Thereby give patients with best possible treatment in light of the existing scientific knowledge.

\section{ACKNOWLEDGMENT}

We would like to express our thanks to the head, Department of Pharmacy Practice and our department staffs to their valuable suggestions and recommendations.

\section{AUTHORS' CONTRIBUTIONS}

All authors have contributed equally.

\section{CONFLICT OF INTEREST}

There are no conflicts of interest to declare.

\section{FUNDING SOURCES}

There are no funding sources, whatsoever, for this study.

\section{REFERENCES}

1. Fitazgibbons RJ, Forse RA. Clinical practice: Groin hernias in adult. N Engl J Med 2015;372:756-63.

2. Rao G, Rao A, Pujara N, Pujara P, Patel S. Prevalence of hernia among fishermen population in Kutch district, India. Natl J Integr Res Med 2015;6:44-51

3. Kingnorth A, LeBlanc KA. Management of abdominal wall hernias. Int J Surg 2003;13:33-9.

4. GBD 2015 Disease and Injury Incidence and Prevalence Collaborators. Global, regional, and national incidence, prevalence and years lived with disability for 310 diseases and injuries, 1990-2015: A systematic analysis for the global burden of disease study 2015. Lancet 2016;388:1545-602.

5. GBD 2015 Mortality and Causes of Death Collaborators. Global, regional, and national life expectancy, all-cause mortality, and cause-specific mortality for 249 causes of death, 1980-2015: A systematic analysis for the global burden of disease study. Lancet 2016;388:1459-544.

6. Chow A, Purkayastha S, Athanasiou T, Tekkis P, Darzi A. Inguinal hernia. Br Med J Clin Evid 2007;4:1-20.

7. Rains AJ, Capper WM. Bailey and love's short practice of surgery. Hernia 2017; 15:57-65

8. Kingsnorth A, Leblanc KA. Hernias: Inguinal and incisional. Lancet 2003;362:1561-71.

9. Townsend C, Beauchamp D, Evers M, Mattox KL, editors. Hernias. In: Sabiston Textbook of Surgery: The Biological Basis of Modern Surgical Practice. $20^{\text {th }}$ ed. Amsterdam, Netherlands: Elsevier; 2017.

10. Kumar BR, Madhusoodhanan N, Balaji A, Poornima MA. Prevalence and risk factors of inguinal hernia-a hospital based observational study. Int J Med Appl Sci 2014;3:191-8.

11. Sangwan M, Sangwan V, Garg M, Mahendirutta P, Garg U. Abdominal wall hernia in a rural population in India: Is spectrum changing? Open J Epidemiol 2013;3:135-8.

12. Lee HK, Park SJ, Yi BH. Multi-detector CT reveals diverse variety of abdominal hernias. J Med Imaging 2010;32:27-31.

13. Rutkow IM. Demographic and socioeconomic aspects of hernia repair in United States in 2003. Surg Clin North Am 2003;83:1045-51.

14. Masoumi A, Ramogida G. Tibialis anterior herniation a rare clinical entity: A case report and review of the literature. J Can Chiropr Assoc 2020;64:88-91.

15. Sharma N, Kumar N, Verma R, Jhobta A. Tibialis Anterior muscle hernia: A case of chronic, dull pain and swelling in leg diagnosed by dynamic ultrasonography. Pol J Radiol 2017;82:293-5.

16. Kupershlyak L, Perry Z, Kirshtein B. Comparison of totally extra peritoneal groin hernia repair with mesh fixation. Int J Abdom Wall Hernia Surg 2019;2:134-41.

17. Sulaiman J, Sahayam SJ, Senthurpandian S, Anandan H. A study of 
incidence of different types of groin hernias in adults. Int J Sci Study 2018;5:87-90.

18. Kamtoh G, Pach R, Kibil W, Matyja A, Solecki R, Banas B, et al. Effectiveness of mesh hernioplasty in incarcerated inguinal hernias. J Clin Med 2014;9:415-9.

19. Garba ES. The pattern of adult external abdominal hernias in Zaria. Niger J Sur Res 2000;2:12-5.

20. Hernia and its Types. Medicinenet; 2019. http://www.medicinenet.com/ hernia/article.htm [Last accessed on 2021 Aug 10].

21. Hernia Diagnosis and Management. Informedhealth; 2016. http:// hernias-informedhealth.0rg [Last accessed on 2020 Aug 18].

22. Mbah N. Morbidity and mortality associated with inguinal hernia in Northwestern Nigeria. West Afr J Med 2007;26:288-92.

23. Constance ER, James E. Risk factors for inguinal hernia among adults in the US population. Am J Epidemiol 2007;165:1154-61.

24. Hernia. BBC Health; 2018. http://www.bbc.co.uk/health/conditions/ hernia1.shtm [Last accessed on 2021 Aug 10].

25. Laparoscopic Inguinal Hernia Repair Surgery. Society of American Gastrointestinal and Endoscopic Surgeons; 2015. Laparoscopic Inguinal Hernia Repair Surgery-Patient Information from SAGES; 2021.

26. Lau H, Fang C, Yuen WK, Patil NG. Risk factors for inguinal hernia in adult males: A case-control study. Surgery 2007;141:262-6.

27. Ein SH, Njere I, Ein A. Six thousand three hundred sixty-one paediatric inguinal hernias: A 35-year review. J Pediatr Surg 2006;41:980-6.

28. Halgas B, Viera J, Dilday J, Bader J, Holt D. Femoral hernias: Analysis of preoperative risk factors and 30-day outcomes of initial groin hernias using ACS-NSQIP. Am Surg 2018;84:1455-61.

29. Niebuhr H, König A, Pawlak M, Sailer M, Köckerling F, Reinpold W. Groin hernia diagnostics: Dynamic inguinal ultrasound (DIUS). Langenbecks Arch Surg 2017;402:1039-45.

30. Paul A, Korenkov M, Peters S, Köhler L, Fischer S, Troidl H. Unacceptable results of the Mayo procedure for repair of abdominal incisional hernias Eur J Surg 1998;164:361-7.

31. Aslani N, Brown CJ. Does mesh offer an advantage over tissue in the open repair of umbilical hernias? A systematic review and metaanalysis. Hernia 2010;14:455-62.

32. Holzinger F, Kapp T, Klaiber C. Laparoscopic hiatal hernia repair: Longterm outcome with the focus on the influence of mesh reinforcement. Surg Endosc 2006;20:380-4.

33. Kaneko T, Funahashi K, Ushigome M, Kagami S, Goto M, Koda $\mathrm{T}$, et al., Incidence of and risk factors for incisional hernia after closure of temporary ileostomy for colorectal malignancy. Hernia 2019;23:743-8.

34. Debrah SA, Okpala AM. Epigastric hernia in pregnancy: A management plan based on a systematic review of literature and a case history. Indian J Surg 2013;75:212-3

35. Vos DI, Scheltinga MR. Incidence and outcome of surgical repair of Spigelian hernia. Br J Surg 2004;91:640-4.

36. Kelly ME, Courtney D, McDermott FD, Heeney A, Maguire D, Geoghegan JG, et al. Laparoscopic spigelian hernia repair: A series of 40 patients. Surg Laparosc Endosc Percutan Tech 2015;25:86-9.

37. Hernia Overview. Emedicinehealth; 2019. http://www.emedicinehealth. com/hernia/page7_em.htm [Last accessed on 2021 Aug 10].

38. Wessem KJ, Simons MP, Plaisier PW. The etiology of indirect inguinal hernias: Congenital and/or acquired? Hernia 2003;7:76-9.

39. Nilsson H, Stranne J, Stattin P, Nordin P. Incidence of groin hernia repair after radical prostatectomy: A population based nationwide study. Ann Surg 2014;259:1223-7.

40. Ruhl CE, Everhart JE. Risk factors for inguinal hernia among adults in the US population. Am J Epidemiol 2007;165:1154-61.

41. Quintas ML, Rodrigues CJ, Yoo JH, Rodrigues AJ Jr. Age related changes in the elastic fiber system of the interfoveolar ligament. Rev Hosp Clin Fac Med Sao Paulo 2000;55:83-6.

42. Magnusson J, Videhult P, Gustafsson U, Nygren J, Thorell A. Relationship between preoperative symptoms and improvement of quality of life in patients undergoing elective inguinal herniorrhaphy. Surgery 2014;155:450-8.

43. Fitzgibbons RJ, Ramanan B, Arya S, Turner SA, Li X, Gibbs JO, et al. Long-term results of a randomized controlled trial of a nonoperative strategy for men with minimally symptomatic inguinal hernias. Ann Surg 2013;258:508-15.

44. Chung L, Norrie J, O'Dwyer PJ. Long-term follow-up of patients with a painless inguinal hernia from a randomized clinical trial. Br J Surg 2011;98:596-9.

45. Kamtoh G. Effectiveness of mesh hernioplasty in incarcerated inguinal hernias. Videosurg Other Miniinvasive Tech 2014;9:415-9.
46. Veerabhadrappa PS, Abhishek S, Shewtauk G. A study of burden and burden and risk factors of inguinal hernia from Western Utter Pradesh, India. Int J Surg 2016;4:377-80.

47. Abdulmajeed AA, Abdulla H, Haider R. Prevalence, risk factors and character of abdominal hernia in Arar City, Northern Saudi Arabia in 2017. Electron Physician 2017;9:4806-11.

48. Rosemar A, Angerås U, Rosengren A. Body mass index and groin hernia: A 34-year follow-up study in Swedish men. Ann Surg 2008;247:1064-8.

49. Vandenberg JC, Valois JC, Go PM, Rosenbusch G. Detection of groin hernia with physical examination, ultrasound, and MRI compared with laparoscopic findings. Invest Radiol 1999;34:739-43.

50. Jamadar DA, Franz MG. Inguinal region hernias. Ultrasound Clin 2007; $2: 711-25$

51. Jamadar DA, Jacobson JA, Morag Y, Girish G, Ebrahim F, Gest T, et al. Sonography of inguinal region hernias. AJR Am J Roentgenol 2006;187:185-90.

52. Korenkov M, Paul A, Troidl H. Color duplex sonography: Diagnostic tool in the differentiation of inguinal hernias. J Ultrasound Med 1999;18:565-8.

53. Burkhardt JH, Arshanskiy Y, Munson JL, Scholz FJ. Diagnosis of inguinal region hernias with axial CT: The lateral crescent sign and other key findings. Radiographics 2011;31:1-12.

54. Zoga AC, Mullens FE, Meyers WC. The spectrum of MR imaging in athletic pubalgia. Radiol Clin North Am 2010;48:1179-97.

55. Rama MR, Balamaddaiah G. Prevalence and risk factors of inguinal hernia: A study in a semi-urban area in Rayalaseema, Andhra Pradesh, India. Int J Surg 2019;3:1310-3.

56. Fitch MT, Manthey DE. A procedure curriculum for medical students. Med Educ 2009;43:1100-8

57. Bobrow RS. The hernia. J Am Board Fam Med 1999;12:95-96.

58. Scherer LR, Grosfeld JL. Inguinal hernia and umbilical anomalies. Pediatr Clin North Am 1993;40:1121-31.

59. Katz DA. Evaluation and management of inguinal and umbilical hernias. Pediatr Ann 2001;30:729-35.

60. Levine BJ, Nabha S, Bouzoukis JK. Chronic inguinal hernia. Int J Emerg Med 1999;17:515-6.

61. Mandarry MT, Zeng SB, Wei ZQ, Zhang C, Wang ZW. Obturator hernia--a condition seldom thought of and hence seldom sought. Int J Colorectal Dis 2012;27:133-41

62. Wantz GE, Schwartz SI, Shires GT, Spencer FC. Abdominal wall hernias. Int J Surg 1994;6:97-102.

63. Mensching JJ, Musielewicz AJ. Abdominal wall hernias. Emerg Med Clin North Am 1996;14:739-56.

64. Martin M, Paquette B, Badet N, Sheppard F, Aubry S, Delabrousse E. Spigelian hernia: CT findings and clinical relevance. Abdom Imaging 2013;38:260-4

65. DeVries PA. The pathogenesis of gastroschisis and omphalocele. J Pediatr Surg 1980;15:245-51

66. Rutkow IM, Robbins AW. Demographic, classificatory, and socioeconomic aspects of hernia repair in the United States. Surg Clin North Am 1993;73:413-26.

67. Rutkow IM. Epidemiologic, economic, and sociologic aspects of hernia surgery in the United States in the 1990s. Surg Clin North Am 1998;78:941-51.

68. Seker G, Kulacoglu H, Öztuna D, Topgül K, Akyol C, Çakmak A, et al. Changes in the frequencies of abdominal wall hernias and the preferences for their repair: A multicenter national study from Turkey. Int Surg 2014;99:534-42

69. Mahon D, Decadt B, Rhodes M. Prospective randomized trial of laparoscopic (transabdominal preperitoneal) vs open (mesh) repair for bilateral and recurrent inguinal hernia. Surg Endosc 2003;17:1386-90.

70. Neumayer L, Giobbie-HA, Jonasson O, Fitzgibbons R Jr., Dunlop D, Gibbs J, et al. Open mesh versus laparoscopic mesh repair of inguinal hernia. N Engl J Med 2004;350:1819-27.

71. McCormack K, Scott NW, Go PM, Ross S, Grant AM, EU hernia trialits collaboration. Laparoscopic techniques versus open techniques for inguinal hernia repair. Cochrane Database Syst Rev 2003;1:1785-6.

72. Kuhry E, van Veen RN, Langeveld HR, Steyerberg EW, Jeekel J, Bonjer HJ. Open or endoscopic total extraperitoneal inguinal hernia repair? A systematic review. Surg Endosc 2007;21:161-6.

73. Memon MA, Cooper NJ, Memon B, Memon MI, Abrams KR. Metaanalysis of randomized clinical trials comparing open and laparoscopic inguinal hernia repair. Br J Surg 2003;90:1479-92.

74. Pokorny H, Klingler A, Schmid T, Fortelny R, Hollinsky C, Kawji R, et al. Recurrence and complications after laparoscopic versus open inguinal hernia repair: Results of a prospective randomized multicenter 
trial. Hernia 2008;12:385-9.

75. Wright D, Paterson C, Scott N, Hair A, O’Dwyer PJ. Five-year followup of patients undergoing laparoscopic or open groin hernia repair: A randomized controlled trial. Ann Surg 2002;235:333-7.

76. Sarli L, Iusco DR, Sansebastiano G, Costi R. Simultaneous repair of bilateral inguinal hernias: A prospective, randomized study of open, tensionfree versus laparoscopic approach. Surg Laparose Endosc Percutan Tech 2001;11:262-7.

77. Collaboration EH. Laparoscopic compared with open methods of groin hernia repair: Systematic review of randomized controlled trials. $\mathrm{Br} \mathrm{J}$ Surg 2000;87:860-7.

78. Liang MK, Berger RL, Li LT, Davila JA, Hicks SC, Kao LS. Outcomes of laparoscopic vs open repair of primary ventral hernias. Surgery 2013;148:1043-8.

79. Sarosi GA. Laparoscopic umbilical and epigastric hernia repair: The procedure of choice? Surgery 2013;148:1049-54.

80. Masic D, Liang E, Long C, Sterk EJ, Barbas B, Rech MA. Intravenous lidocaine for acute pain: A systematic review. Pharmacotherapy 2018;38:1250-9.

81. Barr J, Talmage DE, Sandoval NF, Zomorodi K, Cohane C, Gambus PL, et al. Propofol dosing regimens for ICU sedation based upon an integrated pharmacokinetic pharmacodynamic model. Anesthesiology 2001;95:324-33

82. Ronan KP, Gallagher JT, George B, Hamby B. Comparison of propofol and midazolam for sedation in intensive care unit patients. Crit Care Med 1995;23:286-93.

83. Reves JG, Corssen G, Holcomb C. Comparison of two benzodiazepines for anaesthesia induction: Midazolam and diazepam. Can Anaesth Soc J 1978;25:211-20.

84. Roelofse JA, van der Bijl P. Cardiac dysrhythmias associated with intravenous lorazepam, diazepam, and midazolam during oral surgery.
J Oral Maxillofac Surg 1994;52:247-50.

85. Salcedo-Wasicek MC, Thirlby RC. Postoperative course after inguinal herniorrhaphy. A case-controlled comparison of patients receiving workers' compensation vs patients with commercial insurance. Ann Surg 1995;130:29-32.

86. Barkun JS, Keyser EJ, Wexler MJ, Fried GM, Hinchey EJ, Fernandez M, et al. Short-term outcomes in open vs. laparoscopic herniorrhaphy: Confounding impact of worker's compensation on convalescence. J Gastrointest Surg 1999;3:575-82.

87. Pavlin DJ, Horvath KD, Pavlin EG, Sima K. Pre-incisional treatment to prevent pain after ambulatory hernia surgery. Anesth Analg 2003;97:1627-32.

88. Rettenbacher T, Hollerweger A, Macheiner P, Gritzmann N, Gotwald T, Frass R, et al. Abdominal wall hernias: Cross-sectional imaging signs of incarceration determined with sonography. AJR Am J Roentgenol 2001;177:1061-6.

89. Macari M, Megibow A. Imaging of suspected acute small bowel obstruction. Semin Roentgenol 2001;36:108-17.

90. Martin DF, Williams RF, Mulrooney T, Voeller GR. Ventral mesh in umbilical/epigastric hernia repairs: Clinical outcomes and complications. Hernia 2008;12:379-83.

91. Brandt ML. Pediatric hernias. Surg Clin North Am 2008;88:27-43.

92. Kapur P, Caty MG, Glick PL. Pediatric hernias and hydroceles. Pediatr Clin North Am 1998;45:773-89.

93. Supangat, Muhammad YN, Meiske M. Amyand's hernia associated with mesenteric chylous cyst in infant: A rare case report. BMC Surg 2020;20:93-7.

94. Tanabe K, Mori S, Kita Y, Wada M, Kenji B, Itaru O. A rare case report of bilateral recurrent inguinal hernia due to persistent Mullerian duct syndrome treated by transabdominal preperitoneal repair. Clin Case Rep 2020;99:e19079. 